\title{
Parameterization and Application of Agricultural Best Management Practices in a Rural Ontario Watershed Using PCSWMM
}

\author{
Michael T. Talbot, Olivia McGuire, Cecilio Olivier and Ryan Fleming \\ Emmons \& Olivier Resources, Inc., St. Paul, Minnesota.
}

\begin{abstract}
As agricultural production has continued to expand and intensify around the world, many models have been developed in an attempt to accurately predict the downstream impacts on water quality and quantity due to changes in on-farm management practices. In rural watersheds with complex stormwater conveyance systems, models designed for agricultural landscapes tend to inadequately represent the spatial and temporal resolution required in the simulation of hydraulic systems. The Storm Water Management Model (SWMM) was originally developed for urban watershed modelling, but its robust hydraulic simulation capabilities have been applied in conjunction with new tools developed within PCSWMM in order to simulate the downstream impacts of a suite of agricultural best management practices (BMPs) in a watershed in rural Ontario, Canada. Three simulation scenarios were run and results are reported for a single model subcatchment. Results show general agreement with literature reported nutrient reduction values, but more testing of these capabilities is required.
\end{abstract}

\section{Introduction}

Awareness of the environmental consequences resulting from agricultural production dates back at least to the 1920s with the publication of Soil Erosion: A National Menace (Bennett and Chapline 1928), which some consider the start of modern soil conservation (Renschler and Harbor 2002). The 1960s brought new awareness with the publication of Silent Spring (Carson 1962), which focused not on the denudation of agricultural lands, but instead on the downstream impacts of agricultural practicesspecifically pesticide application - on wildlife. Around the same time came a more general increased awareness surrounding the issue of non-point source (NPS) pollution from agricultural lands, which eventually led to what were, perhaps, some of the first attempts to incentivize the adoption of agricultural best management practices (BMP)—such as conservation tillage_-for purposes beyond soil conservation (Hayes and Young 1982; Logan 1993). More recently, water quality issues in the United States and Canada, such as the widespread contamination of groundwater with nitrates (e.g. Burkart and Stoner 2008) and coastal eutrophication from nitrates (e.g. McLellan et al. 2015) and phosphorus (e.g. Rousseau et al. 2013), continually bring agriculture and NPS pollution back into the public eye.

As agricultural production continues to expand and intensify, and awareness of its environmental impacts continues to increase, it is crucial for scientists and engineers to have the ability to adequately predict the effectiveness of agricultural
BMPs in controlling NPS pollution, as well as their economic feasibility (Rousseau et al. 2013; Xie et al. 2015). Since the 1970s, models have been used to help evaluate the benefits of BMPs to downstream waters, as they can provide predictions for water quantity and quality measures that can be compared with numeric standards. In the time since, numerous models have been developed in order to address the wide range of applicationssometimes niche-in which modelling efforts have been useful (USEPA 2005).

Even with this large selection of available models, it is not always possible to find a model that meets all of the requirements of a particular project. Case in point: in 2010, the Lake Huron Southeast Shores Executive Steering Committee (LHSSESC — now Healthy Lake Huron: Clean Water, Clean Beaches Partnership) set out to develop a physically based model to assist in the location and prioritization of agricultural BMPs along the southeast shore of Lake Huron, based on the realization that, at that time, there was no model in existence that met all of the specific requirements laid out for modelling in rural Ontario (Emmons \& Olivier Resources, Inc. and Computational Hydraulics International 2014). The desired model was required to have certain capabilities in order to accurately model the conditions unique to rural Ontario, including:

1. The ability to model natural, urban and agricultural landscapes at the field and regional scale with BMPs targeted to sediment, phosphorus and nitrogen;

Talbot, M., O. McGuire, C. Olivier and R. Fleming. 2016. "Parameterization and Application of Agricultural Best Management Practices in a Rural Ontario Watershed Using PCSWMM." Journal of Water Management Modeling C400. doi:10.14796/JWMM.C400

(c) CHI 2016. www.chijournal.org ISSN 2292-6062. 
2. The capacity to accurately simulate channels, culverts, bridges and stormwater network hydraulics;

3. The ability to change key input data seasonally to account for diverse crop stages and variability in certain hydrologic parameters over time;

4. The ability to simulate groundwater hydrology, including agricultural subsurface drainage;

5. The capacity to simulate sediment loading due to soil erosion; and

6. The ability to account for in-stream processes for phosphorus and nitrogen depletion.

In addition to these primary requirements, several secondary requirements were defined, including:

1. The ability to simulate snowmelt and spring runoff;

2. The ability to model the effects of backwater and reverse flows; and

3. The capacity to perform both event and continuous simulation modelling.

In the context of these requirements, the confounding factors for model selection necessitating the development of new tools were primarily related to (a) the level of detail and rigor required in hydraulic routing due to the possibility of backwater and reverse flows in flat landscapes; and (b) the importance of accurate representation of stormwater conveyance systems on the landscape, including networks of municipal drains within rural areas. Informed by many reviews and comparisons of models (notably USEPA 2005), the U.S. Environmental Protection Agency's (USEPA) stormwater management model, SWMM, was ultimately chosen over models more typically used in rural areas (e.g. SWAT, HSPF) due to its high spatial and temporal resolution modelling capabilities and its explicit physical representation of channel and pipe hydraulics.

The ultimate goal of this project was to develop a model that met all of the project requirements, and to apply this model to five priority coastal watersheds along the southeast shore of Lake Huron totalling roughly $500 \mathrm{~km}^{2}$ in area-which together are referred to as the Rural Stormwater Management Models (RSWMM). This paper focuses on requirement (1) of this project: the use of a field-scale, GIS based methodology for model parameterization and process representation of a suite of BMPs in SWMM and the resulting model simulations using PCSWMM-a decision support system for SWMM (James et al 2010)—within one of these priority watersheds. A brief overview of the watershed model is given, followed by a description of the methodology. Finally, three simulation scenarios applying three different agricultural BMPs will be demonstrated, along the results of their application within a subcatchment.

\section{Methodology}

\subsection{Study Area}

The Bayfield North watershed is located on the southeastern shore of Lake Huron (Figures 1 and 2) between Goderich and
Bayfield. It is a $39 \mathrm{~km}^{2}$ agricultural watershed entirely within the jurisdiction of the Ausable Bayfield Conservation Authority (ABCA). The watershed is drained by municipal drainage systems, including drainage ditches, tile drains and water and sediment control basins (WASCOB), to twenty small streams draining westerly to Lake Huron. The streams are locally referred to as the North Gullies due the eroded ravines and the longest stream in the watershed is Gully Creek.

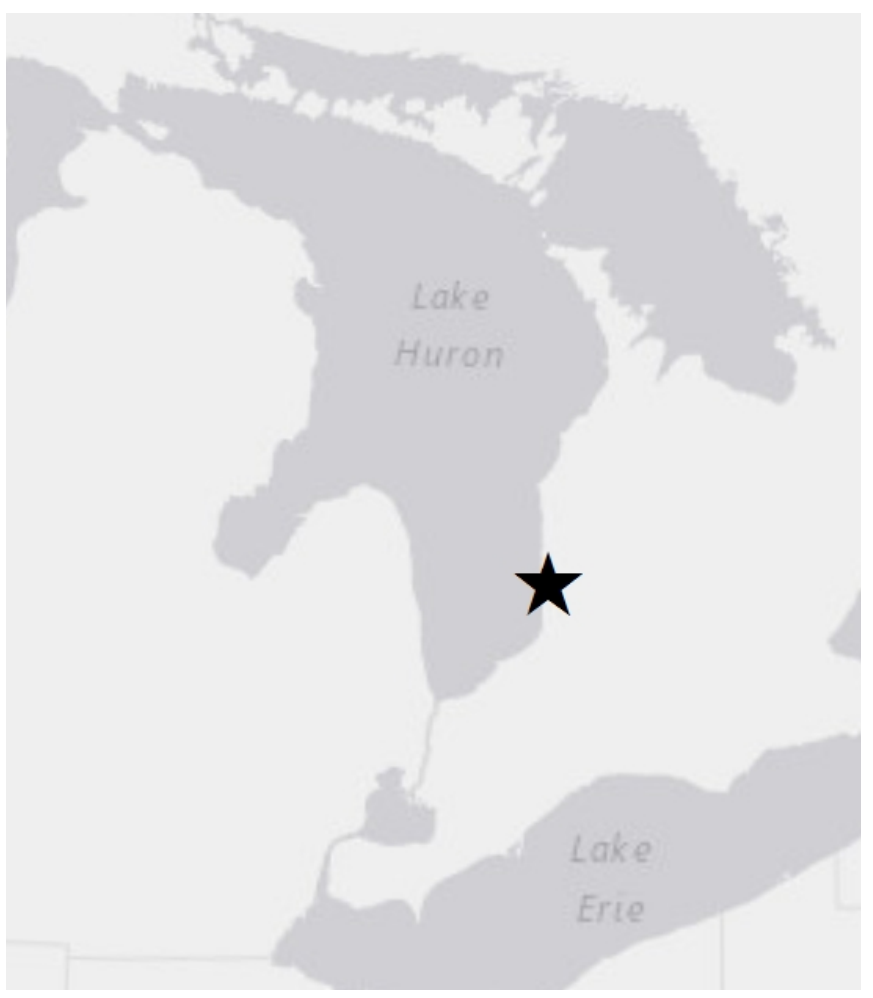

Figure 1 Location of the Bayfield North watershed.

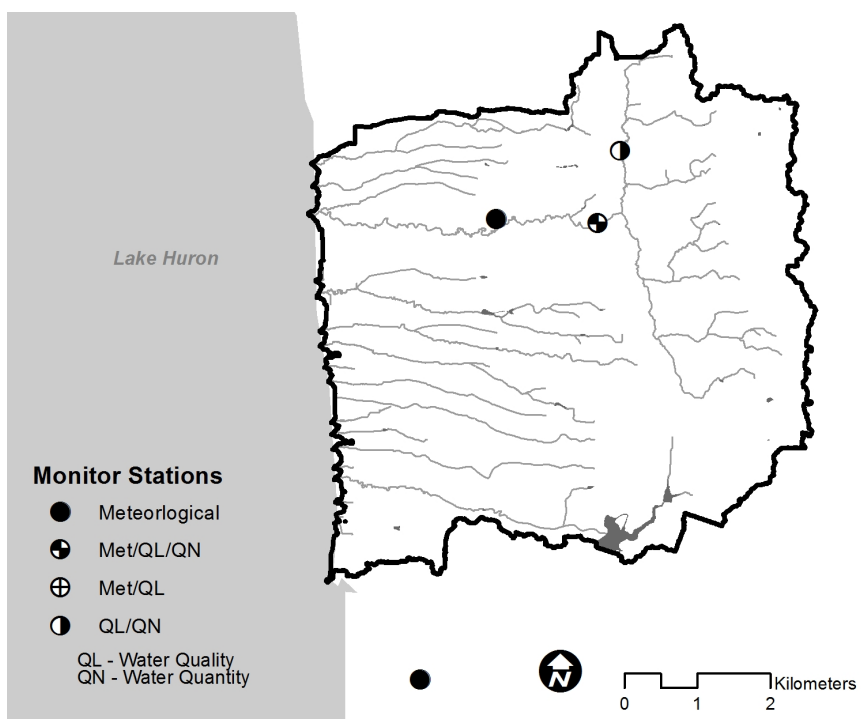

Figure 2 Location of monitoring stations used for model construction and calibration. 
The most dominant land cover category in the watershed is agriculture (57\%) and the main crops cultivated are soybeans, corn and winter wheat. Approximately $28 \%$ of the watershed is forested. Urbanization is limited to rural residential and cottage developments (8\%) throughout the watershed and along the lakeshore. The watershed soils are clay loams, silt loams, loams and sandy loams. The mean annual temperature of the watershed is $7.8^{\circ} \mathrm{C}$ with mean monthly temperatures ranging from $-5.8^{\circ} \mathrm{C}$ in January to $20.7^{\circ} \mathrm{C}$ in July. Mean annual precipitation ranges from about 1000 to $1250 \mathrm{~mm}$ at nearby weather stations with historical records. The longest stream, Gully Creek, is $10 \mathrm{~km}$ long and flows northwesterly at a relatively constant grade of $2.8 \%$ from its headwaters ( $280 \mathrm{~m}$ above sea level) to its outlet into Lake Huron (176 $\mathrm{m}$ above sea level).

The streams in the North Bayfield watershed are cold water fisheries that are important habitats for fish species at risk, such as Redside Dace. The observed nitrate and total phosphorus concentrations at the primary sampling location range from $0.7 \mathrm{mg} / \mathrm{L}$ to $38.7 \mathrm{mg} / \mathrm{L}$ and $0 \mathrm{mg} / \mathrm{L}$ to $5.4 \mathrm{mg} / \mathrm{L}$ respectively. The maximum observed nitrate concentration exceeds the Canadian Water Quality Guideline (CWQG) of $3 \mathrm{mg} / \mathrm{L}$ (CCME 2012), and the maximum observed total phosphorus concentration exceeds the Provincial Water Quality Objectives (PWQO) of 0.03 mg/L (MOEE 1994).

\subsection{Model Description}

\section{SWMM}

The USEPA's Storm Water Management Model (SWMM) has undergone significant periodic upgrades since its original release in 1971, most recently with the release of the SWMM5 engine in 2005. SWMM is a rainfall-runoff model capable of both single event and continuous simulation of runoff quantity and quality from urban and rural landscapes (Metcalf and Eddy, Inc. et al. 1971; James et al. 2010). Hydrology is simulated by treating each catchment as a nonlinear reservoir using Manning's equation and lumped continuity; hydraulics can be simulated by solving the complete Saint-Venant equations (i.e. dynamic wave routing); and water quality can be simulated using one of several forms of buildup and washoff equations for pollutants, with treatment or depletion occurring through the use of mathematical decay expressions (Huber and Dickinson 1992). Although SWMM is a spatially lumped model at the subcatchment scale, discretization of subcatchments is possible to a fine scale and thus, depending somewhat on the level of discretization relative to the size of the study area, SWMM can also be considered distributed or semi-distributed (Sun et al. 2014). Rainfall can be temporally distributed down to minute-scale time steps, as well as spatially distributed if data from more than one gauge is available. Daily values for average windspeed and minimum and maximum temperatures are required for the simulation of snowmelt and snow accumulation, and daily evaporation rates are required to simulate evaporative (E) and evapotranspirative (ET) losses from storage devices (i.e. water surfaces) and subcatchments (i.e. vegetated surfaces) respectively. These daily evaporation rates are used as upper limits on the $\mathrm{E}$ and $\mathrm{ET}$ rates in lieu of a process based representation of these processes. The simulation time steps are defined separately for routing, runoff and reporting; typical values are on the order of seconds, minutes and hours respectively (Huber and Dickinson 1992; James et al. 2010).

\section{Enhancements}

Several additional functionalities were introduced as part of this project. One of these functionalities, the ability to provide monthly multipliers which facilitate the seasonal modification of certain SWMM inputs, was incorporated as a modification to the SWMM code itself in order to satisfy project requirement (3). Along with additional subsequent code modifications, this modified SWMM engine eventual became known as the OpenSWMM engine $(\mathrm{CHI}$ 2015). In order to satisfy project requirement (5), the modified universal soil loss equation (MUSLE) was incorporated into the PCSWMM interface. Daily sediment yield is calculated outside of the SWMM engine, and then these daily estimates are distributed based on SWMM-predicted runoff per the wet period time step (CHI 2014). The resulting estimated total suspended solids (TSS) concentration is then routed conservatively into the hydraulics as a pollutant inflow at the subcatchment outlet, at which point treatment expressions can be applied to represent settling or filtration processes, just as with other SWMM pollutants.

\subsection{Observed Data}

\section{Streamflow Data}

Meteorological data including precipitation, air temperature and wind speed was collected using a DAVIS Vantage Pro2 weather station. The weather station also provided a calculated estimate of reference evapotranspiration using the Penman-Monteith equation. Five months of these data (2013-05-01 to 2013-09-30) collected at three monitoring locations (Figure 2 above), along with gauged streamflow at two monitoring locations (also Figure 2 above) were used for flow calibration, with meteorological data for April used for model warmup. One location had a permanent gauge (GULGUL5), while the other location had a temporary gauge (GULGUL7) that was installed and operated as part of this project. Not enough streamflow data were available at this time to use as a validation dataset.

\section{Water Quality Data}

Water quality samples were collected at both flow monitoring locations and analysed for total suspended solids (TSS), nitrogen (nitrate nitrogen, $\mathrm{NO}_{3}-\mathrm{N}$, nitrite nitrogen, $\mathrm{NO}_{2}-\mathrm{N}$, and total Kjeldahl nitrogen, TKN), and phosphorus (soluble reactive phosphorus, SRP, and total phosphorus, TP). Other water quality indicators were also reported (e.g. ammonium-N, dissolved oxygen), but were not used in model parameterization. Samples were collected using an ISCO automated sampler at the permanent gauge, and grab samples were collected at the temporary gauge. All viable reported concentrations between May 2013 and September 2013 were used for model calibration. Not enough water quality data were available at this time to perform model validation. 


\subsection{Model Setup}

\section{Spatial Datasets}

A portion of the Bayfield North watershed, the Gully Creek subwatershed, has been the subject of both past and ongoing modelling efforts involving the uses of SWAT and imWEBs (Keizer 2014). Partly as a result of these efforts, along with the data collection efforts of the Healthy Lake Huron: Clean Water, Clean Beaches Partnership, a relatively robust GIS dataset was available for use in model parameterization. These data provided by the ABCA included:

- hydrography: digitized watershed boundaries, streams, ditches, municipal drains;

- soil texture (derived from Hoffman et al. 1952);

- land cover, a modified and discretized version of the Provincial Land Cover (2000) Data Base (Smyth 2002), to include agricultural fields and associated cropping and management metadata;

- transportation: digitized roads, culverts and, bridges, including surveyed elevations and measured dimensions;

- digital elevation model (DEM) at $1 \mathrm{~m}$ horizontal resolution; and

- aerial photographs at $0.2 \mathrm{~m}$ resolution.

Subcatchments were initially delineated using ArcHydro (Maidment 2002) and the $1 \mathrm{~m} \mathrm{DEM}$, followed by manual verification in PCSWMM based on contours and aerial photos, resulting in 178 subcatchments having an average of $22 \mathrm{ha}$, a median of $15.5 \mathrm{ha}$, and a range of 1.5 ha to $95 \mathrm{ha}$ in area. A slope raster derived from the DEM was used to initialize the subcatchment slopes within a subcatchment. Infiltration parameters derived from the work of Rawls et al. (1982) were defined for each subcatchment based on the soil texture. Erosion parameters were defined for each soil texture, where the fractions of clay, silt and sand within each soil texture class are derived from the median value of the range of each particle size within a given texture class (as defined by the USDA soil texture classification (Shirazi and Boersma 1984) and the $K$-factor for MUSLE was derived from the work of Wall et al. (1997).

Three subcatchment parameters were determined based on land use. Percent impervious surface was approximated using typical impervious percentages for each land use category, and was determined not to be a sensitive model parameter due to the dominance of pervious area in the landscape upstream of the monitoring station used for calibration. Manning's roughness for pervious surfaces was defined for each land use using values from reports by the U.S. Army Corps of Engineers (USACE 1998) and the Soil Conservation Service (1986), and according to Rossman (2010). Depressional storage was also defined according to Rossman (2010) where possible, and was otherwise estimated by assuming a linear relationship with Manning's roughness based on the suggestion of Onstad (1984) that a correlation exists between these attributes. The roughness of hydraulic elements was estimated based on conduit material using values obtained from
Chow (2009) and the American Society of Civil Engineers (Bizier 2007).

\section{Pollutants}

Seven pollutants were simulated: sand, silt, clay, $\mathrm{NO}_{2}-\mathrm{N}, \mathrm{NO}_{3}-\mathrm{N}$, TKN and SRP. Of these, sand, silt and clay are simulated through PCSWMM's MUSLE routine, and the remainder were simulated using SWMM's washoff equations. Additionally, four pollutants were calculated using PCSWMM's Derive functions: total nitrogen (TN), total suspended solids (TSS), particulate phosphorus (PP), and total phosphorus (TP).

TSS was represented in three parts (sand, silt and clay) to facilitate a more accurate representation of sediment and phosphorus removal via settling than would be possible by simply defining TSS as a pollutant. In this way, a separate treatment expression can be defined for each part. Following a model run, TSS was derived as:

$$
\text { TSS }=\text { Sand }+ \text { Silt }+ \text { Clay }
$$

Phosphorus was considered to be present in two pools: particulate and dissolved (Wetzel 2001). Particulate phosphorus (PP) was derived as:

$$
P P=\text { Sand } * P_{\text {Sand }}+\text { Silt } * P_{\text {Silt }}+\text { Clay } * P_{\text {Clay }}
$$

where $P_{\text {Sand }} P_{\text {Silt }}$ and $P_{\text {Clay }}$ represent the phosphorus content of each particle size, derived from the work of Dong et al. (1983).

The dissolved phosphorus pool was assumed to consist of soluble reactive phosphorus (SRP), often referred to dissolved inorganic phosphorus (Wetzel 2001), and soluble unreactive phosphorus (SUP). While SUP may constitute a non-negligible fraction of total phosphorus (Jarvie et al. 1999; Wetzel 2001), the observed water quality data was only reported for SRP and TP and as such it was not possible to determine the relative magnitude of SUP. Thus, the dissolved component of phosphorus was assumed to be represented solely by SRP as:

$T P=P P+S R P$

Due to observed correlation between SRP and flow rate at selected sampling locations, SRP was parameterized using the Rating Curve form of the washoff equation as suggested by James et al. (2010).

Nitrogen was assumed to be completely accounted for by $\mathrm{NO}_{2}-\mathrm{N}, \mathrm{NO}_{3}-\mathrm{N}$ and TKN. Due to the observed absence of correlation between any of the nitrogen components and flow rate at selected sampling locations, these pollutants were parameterized using the event mean concentration (EMC) form of the washoff equation. Since all three were reported as $\mathrm{mg} / \mathrm{L}$ of nitrogen, total nitrogen was derived as:

$$
\mathrm{TN}=\mathrm{NO}_{2}-\mathrm{N}+\mathrm{NO}_{3}-\mathrm{N}+\mathrm{TKN}
$$

as supported by Kadlec and Knight (1995) and Wetzel (2001).

It is also possible to define concentrations for groundwater outflow in SWMM, although the model does not allow for 
seasonally variable concentrations. These concentrations were defined for $\mathrm{NO}_{2}-\mathrm{N}, \mathrm{NO}_{3}-\mathrm{N}, \mathrm{TKN}$ and SRP using the average concentration of those samples taken during baseflow conditions.

\subsection{Model Calibration}

Calibration was performed for a continuous simulation period from 2013-05-01 to 2013-09-30 for flow data and water quality samples taken at the permanent monitoring location. The temporary monitoring location was not used, due in part to the low number of grab samples taken, and because the timing of the sampling did not line up with peak flows as well as at the permanent location. Calibrations were performed using the sensitivity based radio tuned calibration (SRTC) tool in PCSWMM. The SRTC tool allows users to define tolerances for parameter uncertainty in SWMM layers, and performs model runs at the extremes of this uncertainty range. Once model runs are complete, radio sliders are used to adjust the individual parameters within the predefined uncertainty tolerances and the user is able to dynamically observe the predicted model response, including model performance statistics (if observed data has been imported). The resulting parameters can then be passed back into the model to replace the existing parameters, or they can be used to define a new scenario (Finney and Gharabaghi 2011).

\section{Hydrologic and Hydraulic Calibration}

The most sensitive hydrologic parameters, and those used for calibration, were determined to be pervious depressional storage, pervious Manning's roughness, subcatchment slope, subcatchment width, and the three parameters used in the GreenAmpt infiltration equation. For calibration of stream discharge, hydraulic parameters were not found to be as sensitive as hydrologic parameters and, with the exception of Manning's roughness, hydraulic parameters were generally constrained by survey data and field observations.

Flow data was calibrated for daily and monthly mean flows (Figure 3). Model performance was measured using the coefficient of determination (i.e. $R^{2}$ ) and Nash-Sutcliffe model efficiency (Nash and Sutcliffe 1970), shown in Table 1. July of 2013 had relatively few storm events, and no large storm events, so calibration for those months proved difficult. Overall, the calibration resulted in a good fit with observed daily and monthly mean flows for the simulation period, with NSE $=0.77$ and $R^{2}=0.82$.

Table 1 Model calibration performance statistics and monthly mean flows for 2013.

\begin{tabular}{lcccc}
\hline & & \multicolumn{2}{c}{ Mean Flow $\left(\mathrm{m}^{3} / \mathrm{s}\right)$} \\
\multicolumn{1}{r}{ Period } & NSE & $R^{2}$ & Predicted & Observed \\
\hline May & 0.42 & 0.89 & 0.082 & 0.104 \\
June & 0.31 & 0.53 & 0.061 & 0.048 \\
July & $\mathrm{N} / \mathrm{A}$ & $\mathrm{N} / \mathrm{A}$ & 0.019 & 0.009 \\
August & 0.92 & 0.98 & 0.053 & 0.050 \\
September & 0.74 & 0.94 & 0.053 & 0.026 \\
\multicolumn{1}{c}{ Overall } & 0.77 & 0.82 & 0.054 & 0.047 \\
\hline
\end{tabular}

\section{Water Quality Calibration}

Water quality indicators (parameterized as pollutants in SWMM) were calibrated based on monthly and overall nutrient loading for $\mathrm{NO}_{3}-\mathrm{N}, \mathrm{NO}_{2}-\mathrm{N}, \mathrm{TKN}$ and SRP. The number of usable samples is summarized in Table 2.

Table 2 Summary of water quality samples.

\begin{tabular}{cc}
\hline Pollutant & Number of usable samples \\
\hline $\mathrm{NO}_{2}-\mathrm{N}$ & 12 \\
$\mathrm{NO}_{3}-\mathrm{N}$ & 47 \\
SRP & 46 \\
TSS & 46 \\
TKN & 47 \\
TP & 47 \\
\hline
\end{tabular}

Water quality sampling tended to be both sporadic and clustered (i.e. coincident with particular storm events), providing limited observed data for calibration. For pollutants found to have concentrations correlated to flow, observed loading was estimated by first developing regressions between the concentration of individual samples with flow at the time of sampling. These regressions were then used to interpolate concentrations for all observed flows on an hourly time step, and the resulting

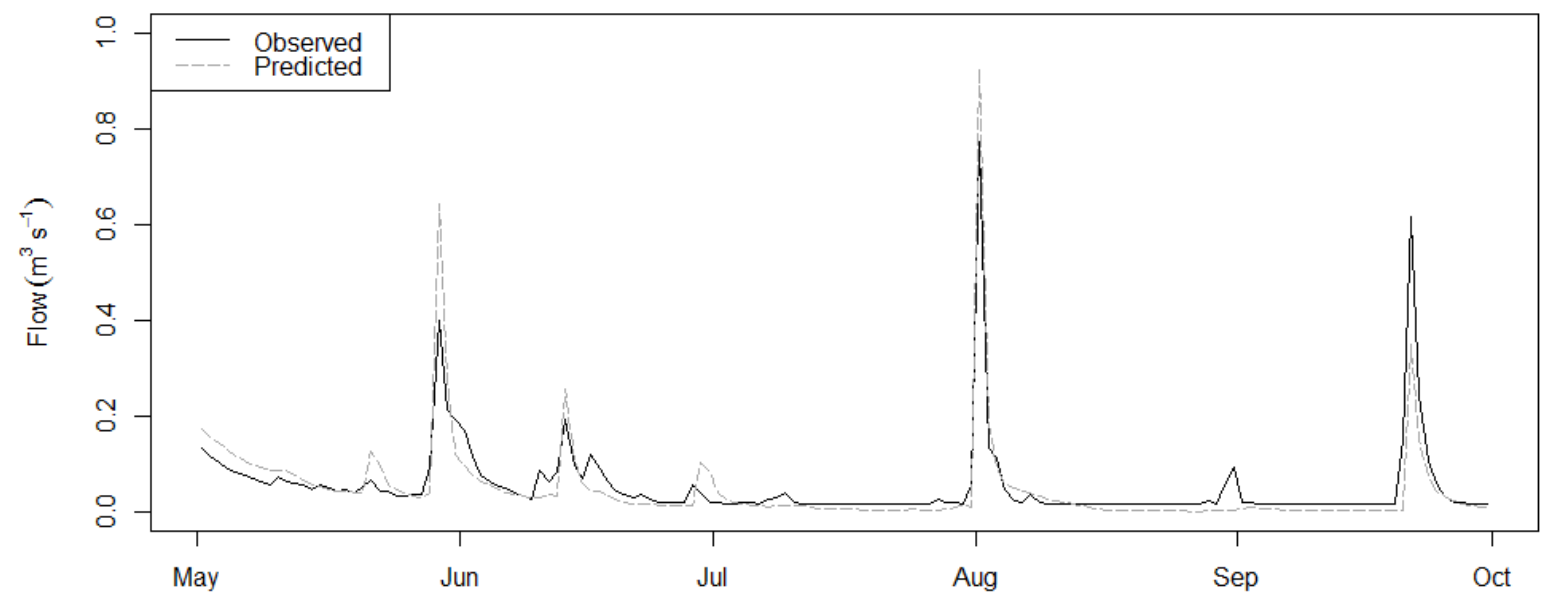

Figure 3 Observed and predicted hydrographs for daily mean discharge in 2013. 
concentrations were multiplied by flow and by the length of the time step to yield a mass load. If no significant correlation existed, an event mean concentration (EMC) was computed for the entire simulation period. EMCs are computed as:

$$
E M C=\frac{\sum_{i=1}^{n} Q_{i} C_{i}}{\sum_{i=1}^{n} Q_{i}}
$$

where:

$$
\begin{aligned}
Q_{i} & =\text { volumetric discharge corresponding to sample } i, \\
C_{i} & =\text { nutrient concentration in sample } i, \text { and } \\
n & =\text { total number of samples. }
\end{aligned}
$$

For $\mathrm{NO}_{3}-\mathrm{N}$, the relationship between concentration and flow varied significantly both within and between events, so concentrations were instead interpolated serially.

Because the MUSLE routine in PCSWMM only takes into account field derived sediment and thus excludes other sources of sediment (e.g. channel bed and bank, and gully erosion), calibration was not performed directly for TSS; rather, observed concentrations were used as checks to ensure that MUSLE-predicted sediment yields were not in excess of measured in-stream loads. Consequently, TP was also not calibrated because predicted TP loads are dependent in the model on predicted particulate phosphorus (PP) loads, which were derived based on an estimated fraction of TSS loads (using the work of Dong et al. 1983). Predicted and observed loads for the four remaining water quality

\begin{tabular}{|c|c|c|c|c|c|c|c|}
\hline & & \multicolumn{5}{|c|}{ Period } & \multirow{2}{*}{ Total } \\
\hline & & May & June & July & August & September & \\
\hline $\mathrm{NO}_{2}-\mathrm{N}$ load & Predicted & 4.9 & 2.0 & 0.30 & 5.6 & 1.9 & 15 \\
\hline \multirow[t]{2}{*}{ (tonnes) } & Observed & 5.6 & 2.7 & 0.42 & 2.1 & 2.4 & 13 \\
\hline & \% Error & $-13 \%$ & $-26 \%$ & $-29 \%$ & $166 \%$ & $-18 \%$ & $12 \%$ \\
\hline $\mathrm{NO}_{3}-\mathrm{N}$ load & Predicted & 1062 & 444 & 67.0 & 1076 & 374 & 3023 \\
\hline \multirow[t]{2}{*}{ (tonnes) } & Observed & 1770 & 1045 & 105 & 416 & 669 & 4004 \\
\hline & \% Error & $-40 \%$ & $-58 \%$ & $-36 \%$ & $159 \%$ & $-44 \%$ & $-24 \%$ \\
\hline SRP load & Predicted & 5.6 & 2.3 & 0.34 & 7.1 & 2.5 & 18 \\
\hline \multirow[t]{2}{*}{ (tonnes) } & Observed & 4.0 & 1.3 & 0.25 & 23.0 & 6.2 & 35 \\
\hline & \% Error & $42 \%$ & $79 \%$ & $33 \%$ & $-69 \%$ & $-60 \%$ & $-49 \%$ \\
\hline TKN load & Predicted & 50 & 25 & 4.9 & 34 & 17 & 131 \\
\hline \multirow[t]{2}{*}{ (tonnes) } & Observed & 27 & 12 & 1.9 & 67 & 34 & 141 \\
\hline & \% Error & $82 \%$ & $115 \%$ & $156 \%$ & $-49 \%$ & $-50 \%$ & $-8 \%$ \\
\hline
\end{tabular}
indicators are shown in Table 3.

Table 3 Monthly predicted and observed nutrient loads for 2013.

\subsection{Parameterization of Agricultural BMPs}

\section{Dynamic Field Shapefile}

Within the model, since the subcatchments are generally much larger than individual farm fields, field scale changes in model parameters are not explicitly represented. However, it was desirable that field level changes hydrology and nutrient loading be reflected accurately at the subcatchment scale. To overcome this, a schema was developed in which the changes in hydrologic parameters predicted to occur as the result of implementing BMPs on a particular field are passed back into the model as changes in the subcatchment parameters using area weighted averages. In this way, the process by which BMPs are implemented could be performed outside of the SWMM engine itself, allowing for more flexibility in future modifications of the process and avoiding the need to modify the SWMM code.

Within PCSWMM, SWMM layers are represented spatially as GIS shapefiles, with model parameters corresponding to shapefile attributes. To implement BMPs on a field scale, a separate shapefile containing polygons representing farm fields is required. In the case of the Bayfield North watershed, this field shapefile was created by modifying the polygons contained in an existing land use shapefile. Setting up BMPs using a field shapefile is facilitated by the ability within PCSWMM to (a) define enforced value lists for attributes; (b) group attributes into customizable categories; and (c) auto-express attributes, which is essentially the ability to define the values of an attribute using an expression. These expressions (auto-expressions) can optionally involve the use of values from one or more of the other attributes in the same shapefile. Auto-expressions were used in conjunction with both user defined and enforced value attributes to develop a network of interdependent attributes that auto-updated a set of dependent attributes based on the selection or implementation of a BMP on a field polygon.

The following six agricultural BMPs can be added to a model using the fields layer to provide pollutant removal, as categorized as avoid or control practices in the Agricultural BMP Handbook for Minnesota (Minnesota Department of Agriculture 2012):

1. Avoid practices:

$$
\begin{aligned}
& \text {. conservation cover; } \\
& \text {. contour farming; and } \\
& \text { cover crops. }
\end{aligned}
$$

2. Control practices:

- conservation tillage; grassed waterways; and terracing.

\section{Pollutant Reduction Mechanisms}

While it would have been possible to simply assign reduction coefficients (i.e. empirical removal efficiencies) for a particular BMP's impact on water quality indicators based on literature values alone, it was desirable to also represent a BMPs impact on runoff rates and volumes as well. To represent the theoretical treatment capabilities of BMPs, the schema was set up such that the activation of a BMP affects relative changes in certain SWMM hydrologic input parameters. First, parameters in the Fields layer are initialized via area weighting from the subcatchments following calibration. Second, BMPs are activated in the Fields layer. Auto-expressions built into the model change and then change the treatment mechanisms assumed for each BMP, summarized below with typical reduction values in Table 4. The overall mechanisms vary between the BMP types as follows:

conservation cover: lowers erosion with permanent vegetation and reduces nutrient applications; 
- contour farming: lowers erosion by directing flow across the slope;

- cover crops: lower erosion with temporary vegetation and reduces nutrient leaching;

- conservation tillage : lowers erosion by retaining residue and vegetation;

- terracing: lowers erosion with reduced slope length; and

- grassed waterways: lower soil erosion with permanent vegetated conveyance.

Table 4 Median values of pollutant reduction by agricultural BMPs as reported in the literature.

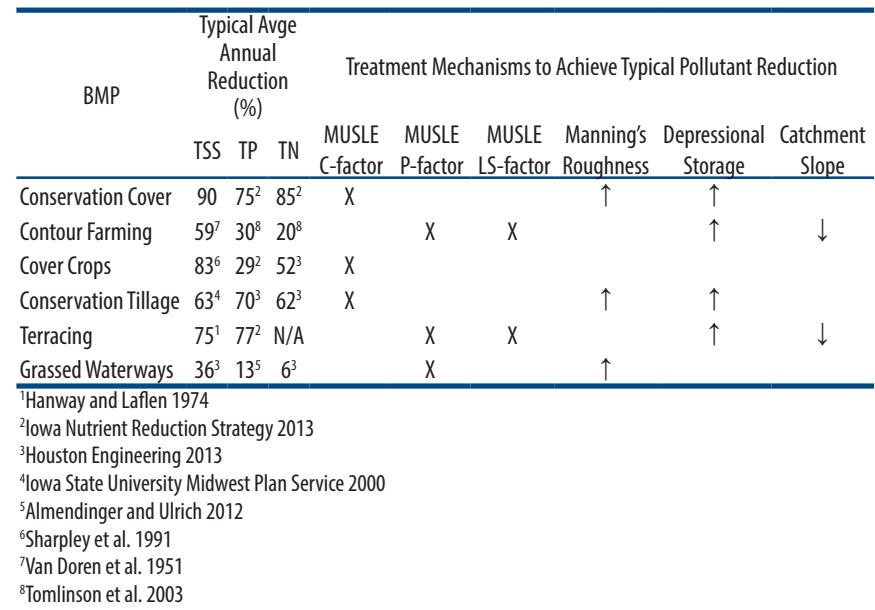

Auto-expressions were developed specifically for each treatment mechanism and BMP combination in Table 4. The relative change in a given parameter was determined from a variety of sources. For the MUSLE C- and P-Factors, values were derived explicitly from RUSLE and USLE documentation (Renard et al. 1997; Wall et al. 1997; Stone and Hilborn 2012). While guidance for the modification of some of the hydrologic parameters also came from these sources, the relative change in these parameters was ultimately determined empirically using a hillslope-scale model calibrated to achieve the median pollutant reduction percentage found in the literature referred to in Table 4. Details of this process and the final auto-expressions are provided in Section 5.2 and Appendix B.2 of the project report available online at http://www. ruralstormwater.com/docs/Rural-Stormwater-Management-Model-Report-FINAL-low-res.pdf.

For example, when a user changes the tillage practice of a field from conventional to conservation tillage, the logic within the auto-expressions:

1. Checks to make sure the land use of that field is agricultural (and not, for example, woodland), else none of the dependent attributes are changed;

2. Checks if other BMPs are also assigned to that field, and takes the maximum resulting values for each dependent attribute; and
3. Modifies Manning's roughness, depressional storage, and the MUSLE C-factor based on the literature suggestions and RUSLE/MUSLE documentation (see Table 4 above).

At this point, the user is free to pass these attribute changes to MUSLE parameters, pervious Manning's roughness, pervious depressional storage, and slope back into the subcatchments of the SWMM model using the area weighting tool in PCSWMM.

\section{Results and Discussion}

The predicted performance of three agricultural BMPs (conservation tillage, conservation cover and contour farming) was assessed using separate simulation scenarios. BMPs were applied to four fields (all cultivated in soybeans under conventional tillage in 2013) that intersect one 89 ha subcatchment (model element SGulyC39) in the easternmost (upstream) portion of the watershed. Together, these fields comprise 54.5 ha (61.2\%) of the subcatchment area. The remaining 34.5 ha were in winter wheat $(24.1 \%)$, corn $(10.2 \%)$, woodland $(3.3 \%)$, and grass/weeds (1.2\%). Results for simulated runoff volume, TSS load, TP load, and TN load for the base condition scenario were compared with the results for each of the three BMP scenarios, as summarized in Table 5.

Table 5 Comparison of selected water quantity and water quality predictions for May 2013 to September 2013 for four management scenarios.

\begin{tabular}{lcccc}
\hline Simulation Scenario & $\begin{array}{c}\text { Runoff Volume } \\
\left(\mathrm{m}^{3}\right)\end{array}$ & TSS load (kg/ha) & TP load (kg/ha) & TN load (kg/ha) \\
\hline Base Conditions & 64610 & 149 & 0.81 & 12.3 \\
Conservation Tillage & 58550 & 91 & 0.50 & 9.1 \\
\% Reduction & $9 \%$ & $39 \%$ & $38 \%$ & $26 \%$ \\
Conservation Cover & 61190 & 118 & 0.65 & 10.6 \\
\% Reduction & $5 \%$ & $21 \%$ & $20 \%$ & $14 \%$ \\
Contour Farming & 64260 & 113 & 0.63 & 12.3 \\
$\quad \%$ Reduction & $1 \%$ & $24 \%$ & $22 \%$ & $0.2 \%$ \\
\hline
\end{tabular}

Due to the dependency on multiple field specific variables, including slope, and also because the subcatchment parameters are the lumped representation of other land uses, these results are difficult to assess without field or subcatchment level monitoring data. However, the reduction percentages for TSS, TP and TN appear to be generally in line with the values from Table 4 above.

\section{Conclusions}

This project set out to develop a model that could meet a set of requirements based on criteria specific to rural Ontario, and to apply that model to five priority watersheds. Focusing on project objective 1, this paper outlined the model construction and calibration for one of these priority watersheds using PCSWMM, and attempted to evaluate the performance of the model in simulating the impacts of assigning three agricultural best management practices to several fields within a model 
subcatchment. Results show that SWMM was able to accurately represent the hydrologic response of a rural watershed, and that it is possible to use SWMM to predict nutrient and sediment loading from agricultural landscapes. Water quality calibrations were adequate, and model performance can likely be improved with the incorporation of additional streamflow and water quality data for use in calibration and validation.

The GIS based schema developed for parameterizing fieldbased agricultural BMPs shows promise as a user friendly methodology that facilitates the modification of model parameters in a structured but customizable fashion. More testing is needed to determine the method's accuracy in predicting the downstream water quality and quantity impacts of BMPs. However, this methodology could be applied as it has been developed to assess the relative impacts of BMP implementation as part of a BMP or site prioritization process.

\section{Acknowledgments}

Funding for this project was provided by the Ontario Ministry of the Environment and Climate Change (MOECC). Streamflow, water quality and field data used in this work were collected by the Healthy Lake Huron: Clean Water, Clean Beaches Partnership. The authors would like to extend special thanks to staff at $\mathrm{ABCA}$ and at $\mathrm{CHI}$ for their support and responsiveness throughout the project.

\section{References}

Almendinger, J. E. and J. S. Ulrich. 2012. "Reductions in Phosphorus Loading In the Sunrise River Watershed from Selected Agricultural Best Management Practices (BMPs)." St. Paul, MN: Science Museum of Minnesota. St. Croix Watershed Research Station Fact Sheet. https://www.smm.org/sites/default/files/public/scwrs/2012.sunAgScen_fs.pdf

Bennett, H. H. and W. R. Chapline. 1928. Soil Erosion: A National Menace. Washington, DC: USDA Soil Conservation Service. Circular 33.

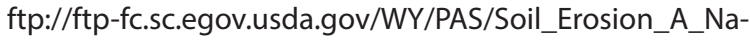
tional_Menace1928.pdf.

Bizier, P., ed. 2007. Gravity Sanitary Sewer Design and Construction, 2nd ed. Reston, VA: American Society of Civil Engineers.

Burkart, M. R., and J. D. Stoner. 2008. “Nitrogen in Groundwater Associated with Agricultural Systems." Chap. 7 in Nitrogen in the Environment, 2nd ed, edited by J. L. Hatfield and R. F. Follett, 177-202. San Diego: Academic Press. http://www.sciencedirect.com/science/article/pii/ B978012374347300007X.

Carson, R. 1962. Silent Spring. Boston: Houghton Mifflin.

CCME (Canadian Council of Ministers of the Environment). 2012. Canadian Water Quality Guidelines for the Protection of Aquatic Life: Nitrate lon. Winnipeg: Canadian Council of Ministers of the Environment.
CHI. 2014. MUSLE (Modified Universal Soil Loss Equation). Guelph: CHI Support. http://support.chiwater.com/support/solutions/articles/174080-musle-modified-universal-soil-loss-equation-erosion.

CHI. 2015. Open SWMM 5.1.907 Code Viewer. Guelph: CHI Open SWMM.

https://www.openswmm.org/SWMM51907/.

Chow, V. T. 2009. Open-Channel Hydraulics. Caldwell, NJ: The Blackburn Press.

Dong, A., G. V. Simsiman and G. Chesters. 1983. “Particle-Size Distribution and Phosphorus Levels in Soil, Sediment, and Urban Dust and Dirt Samples from the Menomonee River Watershed, Wisconsin, U.S.A." Water Research 17 (5): 569-77. doi:10.1016/0043-1354(83)90116-1.

Emmons \& Olivier Resources, Inc. and Computational Hydraulics International. 2014. Development of a Rural Stormwater Management Model to Manage Water Quality in Lake Huron Watersheds. Final Report.

http://www.ruralstormwater.com/docs/Rural-StormwaterManagement-Model-Report-FINAL-low-res.pdf.

Finney, K. and B. Gharabaghi. 2011. “Using the PCSWMM 2010 SRTC Tool to Design a Compost Biofilter for Highway Stormwater Runoff Treatment." Journal of Water Management Modeling 2011:R241-09. doi:10.14796/JWMM.R241-09.

Hanway, J. J. and J. M. Laflen. 1974. "Plant Nutrient Losses from Tile-Outlet Terraces." Journal of Environmental Quality 3 (4): 351-6. doi:10.2134/jeq1974.00472425000300040011x.

Hayes, W. A. and H. M. Young. 1982. Minimum Tillage Farming. Brookfield, Wl: No-Till Farmer, Inc.

Hoffman, D. W., N. R. Richards and F. F. Morwick. 1952. Soil Survey of Huron County. Guelph: Experimental Farms Service, Canada Department of Agriculture and The Ontario Agricultural College. Report No. 13 of the Ontario Soil Survey. http://sis.agr.gc.ca/cansis/publications/surveys/on/on13/ index.html.

Houston Engineering. 2013. Ag BMP Database: Online Version. Fargo, ND: Houston Engineering. http://agbmp.houstoneng.net/ag-bmp-database/.

Huber, W. C., and R. E. Dickinson. 1992. Storm Water Management Model, Version 4: User's Manual. Athens, GA: U.S. Environmental Protection Agency.

lowa Nutrient Reduction Strategy. 2013. lowa Nutrient Reduction Strategy: A Science and Technology Based Framework to Assess and Reduce Nutrients to lowa Waters and the Gulf of Mexico. Ames, IA: University of lowa, lowa Nutrient Research Center. http://www.nutrientstrategy.iastate.edu.

lowa State University Midwest Plan Service. 2000. Conservation Tillage Systems and Management Handbook: Crop Residue 
Management with No-Till, Ridge-Till, Mulch-Till and Strip-Till, 2nd ed. Ames, IA: lowa State University Midwest Plan Service. MWPS-45. ISBN 0-089373-088-2.

James, W., L. A. Rossman and W. R. C. James. 2010. User's Guide to SWMM5, 13th ed. Guelph: CHI Press. R242.

Jarvie, H. P., J. A. Withers and C. Neal. 1999. “Review of Robust Measurement of Phosphorus in River Water: Sampling, Storage, Fractionation and Sensitivity." Hydrology and Earth System Sciences 6 (1): 113-31. doi:10.5194/hess-6-113-2002.

Kadlec, R. H. and R. L. Knight. 1995. Treatment Wetlands, 1st ed. Boca Raton, FL: CRC Press.

Keizer, Y. 2014. Testing the Applicability of the imWEBs Model for Simulating Sediment and Flow in the Gully Creek Watershed. Enschede: University of Twente. Student thesis. http://essay.utwente.nl/65158/.

Logan, T. J. 1993. “Agricultural Best Management Practices for Water Pollution Control: Current Issues." Agriculture, Ecosystems \& Environment 46 (1-4): 223-31. doi:10.1016/0167-8809(93)90026-L.

Maidment, D. R. 2002. Arc Hydro: GIS for Water Resources. Redlands, CA: Esri Press.

McLellan, E., D. Robertson, K. Schilling, M. Tomer, J. Kostel, D. Smith and K. King. 2015. "Reducing Nitrogen Export from the Corn Belt to the Gulf of Mexico: Agricultural Strategies for Remediating Hypoxia." JAWRA Journal of the American Water Resources Association 51 (1): 263-89. doi:10.1111/jawr.12246.

Metcalf and Eddy, Inc., University of Florida and Water Resources Engineers, Inc. 1971. Storm Water Management Model, Vol. I. Final Report 11024DOC07/71 (NTIS PB-203289). Washington, DC: U.S. Environmental Protection Agency.

Minnesota Department of Agriculture. 2012. The Agricultural BMP Handbook for Minnesota. St Paul, MN: Minnesota Department of Agriculture.

MOEE (Ontario Ministry of Environment and Energy). 1994. Water Management: Policies, Guidelines, Provincial Water Quality Objectives. Toronto: Queen's Printer for Ontario. https://www.ontario.ca/document/water-management-policies-guidelines-provincial-water-quality-objectives.

Nash, J. E., and J. V. Sutcliffe. 1970. “River Flow Forecasting through Conceptual Models Part 1 - A Discussion of Principles." Journal of Hydrology 10 (3): 282-90. doi:10.1016/0022-1694(70)90255-6.

Onstad, C. A. 1984. "Depressional Storage on Tilled Soil Surfaces." Transactions of the ASAE 27 (3): 729-32. doi:10.13031/2013.32861.

Rawls, W. J., D. L. Brakensiek and K. E. Saxtonn. 1982. “Estimation of Soil Water Properties." Transactions of the ASAE 25 (5): 1316-20. doi:10.13031/2013.33720.
Renard, K. G., G. R. Foster, G. A. Weesies, D. K. McCool and D. C. Yoder. 1997. Predicting Soil Erosion by Water: A Guide to Conservation Planning with the Revised Universal Soil Loss Equation (RUSLE). Tucson, AZ: U.S. Department of Agriculture, Agricultural Research Service. Agriculture Handbook Number 703

Renschler, C. S. and J. Harbor. 2002. "Soil Erosion Assessment Tools from Point to Regional Scales-The Role of Geomorphologists in Land Management Research and Implementation." Geomorphology 47 (2-4): 189-209. doi:10.1016/S0169-555X(02)00082-X.

Rossman, L. A. 2010. Storm Water Management Model User's Manual. Cincinnati, OH: U.S. Environmental Protection Agency.

Rousseau, A. N., S. Savary, D. W. Hallema, S. J. Gumiere and É. Foulon. 2013. "Modeling the Effects of Agricultural BMPs on Sediments, Nutrients, and Water Quality of the Beaurivage River Watershed (Quebec, Canada)." Canadian Water Resources Journal/Revue canadienne des ressources hydriques 38 (2): 99-120. doi:10.1080/07011784.2013.780792.

Sharpley, A. N. and S. J. Smith. 1991. "Effect of Cover Crops on Surface Water Quality." In Cover Crops for Clean Water: The Proceedings of an International Conference, West Tennessee Experiment Station, April 9-11, 1991, Jackson, Tennessee. edited by W. L Hargrove, 41-9. Ankeny, IA: Soil and Water Conservation Society.

Shirazi, M. A., and L. Boersma. 1984. "A Unifying Quantitative Analysis of Soil Texture." Soil Science Society of America Journal 48 (1): 142-47.

Smyth, I. 2002. Provincial Landcover 2000 - 27 Classes. Ontario Ministry of Natural Resources.

Soil Conservation Service. 1986. Urban Hydrology for Small Watersheds. Washington, DC: U.S. Department of Agriculture. Technical Release TR-55.

Stone, R. P. and D. Hillborn. 2012. Universal Soil Loss Equation (USLE) Fact Sheet. Guelph: Ontario Ministry of Agriculture, Food and Rural Affairs. http://www.omafra.gov.on.ca/english/engineer/ facts/12-051.htm.

Sun, N., M. Hall, B. Hong and L. Zhang. 2014. “Impact of SWMM Catchment Discretization: Case Study in Syracuse, New York." Journal of Hydrologic Engineering 19 (1): 223-34. doi:10.1061/(ASCE)HE.1943-5584.0000777.

Tomlinson, P., J. Roe, D. Devlin, J. DeRouchey, J. Leatherman, N. Nelson, A. Sheshukov, C. Rice, D. R. Diaz and P. Barnes. 2003. Water Quality Best Management Practices, Effectiveness, and Cost for Reducing Contaminant Losses from Cropland. Manhattan, KS: Kansas State University Agricultural Experiment Station and Cooperative Extension Service. MF2572 (Rev.). http://www.bookstore.ksre.ksu.edu/pubs/MF2572.pdf. 
USACE. 1998. HEC-1 Flood Hydrograph User's Manual. Davis, CA: U.S. Army Corps of Engineers Hydrologic Engineering Center. CPD-1A.

USEPA. 2005. TMDL Model Evalulation and Research Needs. Cincinatti, OH: U.S. Environmental Protection Agency. EPA/600/R-05/149. doi:10.1.1.125.301.

Van Doren, C. A., R. S. Stauffer and E. H. Kidder. 1951. “Effect of Contour Farming on Soil Loss and Runoff." Soil Science Society of America Journal 15 (C): 413. doi:10.2136/sssaj1951.036159950015000C0093x.
Wall, G. J., D. R. Coote, E. A. Pringle and I. J. Shelton, eds. 1997. RUSLEFAC-Revised Universal Soil Loss Equation for Application in Canada: A Handbook for Estimating Soil Loss from Water Erosion in Canada. Ottawa: Research Branch, Agriculture and Agri-Food Canada. AAFC/AAC2244E.

Wetzel, R. G. 2001. Limnology: Lake and River Ecosystems, 3rd ed. San Diego: Academic Press.

Xie, H., L. Chen and Z. Shen. 2015. "Assessment of Agricultural Best Management Practices Using Models: Current Issues and Future Perspectives." Water 7 (3): 1088-1108. doi:10.3390/w7031088. 